\title{
High expression level of CD44v8-10 in cancer stem-like cells is associated with poor prognosis in esophageal squamous cell carcinoma patients treated with chemoradiotherapy
}

\author{
Takuma Kagami ${ }^{1}$, Mihoko Yamade ${ }^{1}$, Takahiro Suzuki ${ }^{1}$, Takahiro Uotani ${ }^{1}$, Shinya \\ Tani $^{2}$, Yasushi Hamaya ${ }^{1}$, Moriya Iwaizumi ${ }^{3}$, Satoshi Osawa ${ }^{2}$, Ken Sugimoto ${ }^{1}$, Satoshi \\ Baba $^{4}$, Haruhiko Sugimura ${ }^{5}$, Hiroaki Miyajima ${ }^{1}$ and Takahisa Furuta ${ }^{6}$ \\ ${ }^{1}$ First Department of Medicine, Hamamatsu University School of Medicine, Hamamatsu, Japan \\ ${ }^{2}$ Department of Endoscopic and Photodynamic Medicine, Hamamatsu University School of Medicine, Hamamatsu, Japan \\ ${ }^{3}$ Department of Laboratory Medicine, Hamamatsu University School of Medicine, Hamamatsu, Japan \\ ${ }^{4}$ Department of Diagnostic Pathology, Hamamatsu University School of Medicine, Hamamatsu, Japan \\ ${ }^{5}$ Department of Tumor Pathology, Hamamatsu University School of Medicine, Hamamatsu, Japan \\ ${ }^{6}$ Center for Clinical Research, Hamamatsu University School of Medicine, Hamamatsu, Japan \\ Correspondence to: Takuma Kagami, email: t.kagami@hama-med.ac.jp \\ Keywords: cancer stem-like cell; CD44v8-10; esophageal cancer; chemoradiotherapy; sulfasalazine \\ Received: July 09, $2018 \quad$ Accepted: September 13, $2018 \quad$ Published: October 09, 2018 \\ Copyright: Kagami et al. This is an open-access article distributed under the terms of the Creative Commons Attribution License 3.0 (CC BY \\ 3.0), which permits unrestricted use, distribution, and reproduction in any medium, provided the original author and source are credited.
}

\section{ABSTRACT}

Background: Strong reactive oxygen species (ROS) suppression in cancer stemlike cell components in various solid tumors is associated with therapeutic resistance. In this study, we investigated the influence of CD44v8-10 expression on the overall survival of esophageal squamous cell carcinoma (E-SCC) patients after definitive chemoradiotherapy (dCRT) and on radio-sensitivities of E-SCC cell lines treated with or without sulfasalazine, a CD44v8-10-xCT-GSH axis inhibitor.

Methods: Seventy-three patients with E-SCC who received dCRT were examined retrospectively. CD44v8-10 expression was analyzed immunohistochemically using paraffin-blocked pre-dCRT biopsy specimens obtained by esophagoscopy and was expressed as a histo-score ( $\mathrm{H}$-score). The relationship between the H-score and overall survival was analyzed. From human E-SCC cell lines (T.T, T.Tn, or Kyse-3650), we collected CD44v8-10 ${ }^{\text {High }}$ and CD44v8-10 ${ }^{\text {Low }}$ subpopulations using a cell sorter. Water-soluble tetrazolium salt-8 (WST), glutathione-SH (GSH) and ROS assays were performed to compare the effect of sulfasalazine on the radio-sensitivities of these subpopulations in T.Tn and Kyse-3650.

Results: High CD44v8-10 expression was independently associated with poor prognosis in E-SCC patients treated with dCRT (hazard ratio $=2.906,95 \% \mathrm{CI}=$ 1.277-6.611, $p=0.011)$. In CD44v8-10 ${ }^{\text {High }}$ cells of each cell line, sulfasalazine decreased cellular GSH levels, resulting in increased radiation-induced ROS and reduced cell viability. In contrast, sulfasalazine had no significant effects in CD44v8$10^{\text {Low }}$ cells.

Conclusion: High CD44v8-10 expression was an independent prognostic factor in E-SCC patients treated with dCRT. CD44v8-10-xCT-GSH axis inhibition sensitized CD44v8-10 ${ }^{\text {High }}$ E-SCC cells to ROS-inducing treatments such as radiotherapy. Targeting CD44v8-10-XCT-GSH axis may improve the prognosis of post-dCRT E-SCC patients. 


\section{INTRODUCTION}

CD44 is a cell adhesion molecule of the extracellular matrix and has many functions in leucocyte homing/ activation, wound healing, cell migration, and tumor invasion/metastasis [1-3]. CD44 has many splice-variant isoforms, which contribute to heterogeneity in tumor cells. The CD44 isoform containing variant exon $9(\mathrm{CD} 44 \mathrm{v} 9)$ is a known marker for cancer stem-like cells in many types of cancers. Therapeutic resistance of cancer stem-like cells has been identified in various solid tumors. CD44v9 was first reported as a cell surface marker associated with recurrence and mortality for gastric cancer in 1993 [4]. CD44v8-10 has subsequently been associated with poor prognosis in various cancers. However, CD44v8-10 expression in esophageal cancer and its clinical significance have not been fully elucidated.

A randomized controlled study in 1992 and accompanying long-term follow up study in 1999 conducted on esophageal squamous cell carcinoma (E-SCC) suggested that definitive chemoradiotherapy (dCRT; regimen: cisplatin [CDDP] + 5-fluorouracil [5-FU]) was superior to radiotherapy $[5,6]$. Clinical trials of dCRT were subsequently initiated in Japan in unresectable esophageal cancer patients with distant lymph node metastasis (cT4/ cM1-lym). After verifying the therapeutic effectiveness and manageable tolerability of the treatment in these patients (median survival time, 9-13.6 months; 3 year survival rate, $23-30 \%$ ) [7-10], a subsequent clinical trial was performed in resectable clinical stage (cStage) esophageal cancer patients [11-15]. Therefore, in Japan, dCRT is the standard treatment even for patients with cStage IVA or cStage IVB (cM1-lym) esophageal cancer [16]. However, post-complete response (post-CR; RECIST guideline version 1.1) recurrence is often observed and is an important clinical problem. The role of CD44v8-10 in the above-mentioned prognosis of esophageal cancer patients after dCRT is unclear.

One mechanism that may underlie the therapeutic resistance of cancer stem-like cells is their strong ability to suppress reactive oxygen species (ROS). CD44v8-10 expression at the surface of cancer stem-like cells is known to reduce cellular ROS levels by increasing cellular glutathione-SH (GSH) levels via xCT subunit of cystine/glutamate antiporter (system Xc-) (Figure 1) [17]. Interestingly, sulfasalazine (SSZ), a therapeutic agent for inflammatory bowel disease, specifically inhibits CD44v8-10-xCT-GSH axis and decreases cancer stem-like cell proliferation in a xenograft model [18]. In contrast, cellular GSH reportedly acts to protect cells against radiation-induced ROS [19]. Based on these evidences, we hypothesize that the high cellular GSH of CD44v8-10 High cancer stem-like cells may provide them with enhanced resistance against radiation-induced ROS. Moreover, we hypothesized that suppressing the cellular GSH level with SSZ might improve the radio-sensitivity of CD $44 \mathrm{v} 8-10^{\mathrm{High}}$ cancer stem-like cells.
We retrospectively examined the clinical role of CD44v8-10 in E-SCC patients treated with dCRT. We also studied the effect of SSZ, a specific inhibitor of CD44v8-10-xCT-GSH axis, on the radio-sensitivity of E-SCC cells.

\section{RESULTS}

\section{Clinical study}

\section{Influence of CD44v8-10 expression on overall survival}

Characteristics of 73 patients were shown in Table 1. In these patients, univariate analysis showed that performance status (PS), tumor size, cStage and high CD44v8-10 expression (histo-score $[\mathrm{H}$-score $] \geq 151$ ) were associated with poor prognosis (hazard ratio $[\mathrm{HR}]=2.975$, $95 \%$ confidential interval $[\mathrm{CI}] 1.431-6.186, p=0.004$; $\mathrm{HR}=3.755,95 \% \mathrm{CI} 1.784-7.903, p<0.001 ; \mathrm{HR}=5.177$, 95\% CI 2.448-10.946, $p<0.001 ; \mathrm{HR}=3.438,95 \%$ CI $1.549-7.631, p=0.002$, respectively) (Table 2). Moreover, multivariate analysis showed that cStage and high CD44v8-10 expression were independent poor prognostic factors $(\mathrm{HR}=3.536,95 \%$ CI $1.176-10.626$, $p=0.024 ; \mathrm{HR}=2.844,95 \%$ CI $1.248-6.479, p=0.013$, respectively).

The Cox proportional hazard model using CD44v8-10 expression (H-score) as a continuous variable further confirmed that CD44v8-10 was an independent poor prognostic factor for overall survival $(\mathrm{HR}=1.009$, 95\% CI 1.004-1.015, $p=0.002$ for CD44v8-10 expression in univariate analysis; $\mathrm{HR}=1.008,95 \%$ CI $1.002-1.014$, $p=0.009$ for $\mathrm{CD} 44 \mathrm{v} 8-10$ expression in multivariate analysis). This suggests that the cut off value of $\mathrm{H}$-score was not a critical factor in this analysis.

Figure 2 shows the Kaplan-Meier curves for CD44v8-10 expression and overall survival. Overall survival of E-SCC patients with high CD44v8-10 expression was significantly shorter than that of E-SCC patients with low CD44v8-10 expression ( $p=0.001$, Figure 2A). Stratification of subjects by cStage showed no statistically significant difference in overall survival between cStage I (cT1b) subjects with high and low CD44v8-10 expression because of the lack of diseasespecific death $(p=0.439$, Figure 2B). In contrast, overall survival of cStage II + III and cStage IVA + IVB (cM1lym) subjects with high CD44v8-10 expression was significantly shorter than that of subjects of corresponding stages with low CD44v8-10 expression ( $p=0.024$, Figure 2C; $p=0.023$, Figure 2D, respectively).

\section{CD44v8-10 expression and clinicopathological variables}

We investigated the association between CD44v8-10 expression and clinicopathological variables (Table 3). In univariate analysis, no clinicopathological variable met a significance level of 0.050 . Tumor size, depth of 
Table 1: Characteristics of subjects with esophageal squamous cell carcinoma (E-SCC)

\begin{tabular}{|c|c|c|}
\hline Age & Mean $\pm \mathrm{SD},(\mathrm{y})$ & $69 \pm 8.2$ \\
\hline \multirow{2}{*}{ Gender } & Male & $61(83.6 \%)$ \\
\hline & Female & $12(16.4 \%)$ \\
\hline Height & Mean $\pm \mathrm{SD},(\mathrm{cm})$ & $161.1 \pm 8.0$ \\
\hline Weight & Mean $\pm \mathrm{SD},(\mathrm{kg})$ & $53.9 \pm 8.8$ \\
\hline eGFR & Mean $\pm \mathrm{SD},\left(\mathrm{ml} / \mathrm{min} / 1.73 \mathrm{~m}^{2}\right)$ & $78 \pm 20.5$ \\
\hline \multirow{4}{*}{ PS } & 0 & $18(24.7 \%)$ \\
\hline & 1 & $39(53.4 \%)$ \\
\hline & 2 & $16(21.9 \%)$ \\
\hline & 3 & $0 \quad(0.0 \%)$ \\
\hline \multirow[t]{3}{*}{ Tumor size } & Median with range, $(\mathrm{cm})$ & $5.0(1.0-10.5)$ \\
\hline & $\mathrm{Ce}$ & $9(12.3 \%)$ \\
\hline & $\mathrm{Ut}$ & $11(15.1 \%)$ \\
\hline \multirow[t]{4}{*}{ Tumor location (primary site) } & $\mathrm{Mt}$ & $35(47.9 \%)$ \\
\hline & $\mathrm{Lt}$ & $18(24.7 \%)$ \\
\hline & EGJ & $0 \quad(0.0 \%)$ \\
\hline & Well differentiated SCC & $10(13.7 \%)$ \\
\hline \multirow{6}{*}{ Histological type } & Moderately differentiated SCC & $54(74.0 \%)$ \\
\hline & Poorly differentiated SCC & $9(12.3 \%)$ \\
\hline & Basaloid SCC & $0 \quad(0.0 \%)$ \\
\hline & cTis & $0 \quad(0.0 \%)$ \\
\hline & cTla & $0 \quad(0.0 \%)$ \\
\hline & $\mathrm{cT} 1 \mathrm{~b}$ & $15(20.5 \%)$ \\
\hline \multirow[t]{5}{*}{ Depth of invasion } & $\mathrm{cT} 2$ & $9(12.3 \%)$ \\
\hline & $\mathrm{cT} 3$ & $22(30.1 \%)$ \\
\hline & $\mathrm{cT} 4 \mathrm{a}$ & $12(16.4 \%)$ \\
\hline & $\mathrm{cT} 4 \mathrm{~b}$ & $15(20.5 \%)$ \\
\hline & $\mathrm{cNO}$ & $24(32.9 \%)$ \\
\hline \multirow{4}{*}{ Lymph node metastasis } & $\mathrm{cN} 1$ & $12(16.4 \%)$ \\
\hline & $\mathrm{cN} 2$ & $32(43.8 \%)$ \\
\hline & $\mathrm{cN} 3$ & $5(6.8 \%)$ \\
\hline & cM0 & $63(86.3 \%)$ \\
\hline \multirow[t]{5}{*}{ Distant metastasis } & cM1-lym & $10(13.7 \%)$ \\
\hline & cM1-hematogenous or (pleural/peritoneal) dissemination & $0(0.0 \%)$ \\
\hline & 0 & $0(0.0 \%)$ \\
\hline & I & $14(19.2 \%)$ \\
\hline & II & $8(11.0 \%)$ \\
\hline \multirow[t]{4}{*}{ cStage, UICC 8th } & III & $16(21.9 \%)$ \\
\hline & IVA & $25(34.2 \%)$ \\
\hline & IVB (cM1-lym) & $10(13.7 \%)$ \\
\hline & IVB with hematogenous metastasis or (pleural/peritoneal) dissemination & $0(0.0 \%)$ \\
\hline $\begin{array}{l}\text { Number of pre-CRT tumor } \\
\text { biopsy sample }\end{array}$ & Median with range, $(\mathrm{n})$ & $2(1-6)$ \\
\hline CD44v8-10 expression & Median with range, (H-score) & $180(5-300)$ \\
\hline
\end{tabular}

Abbreviations: SD, standard deviation; eGFR, estimated glomerular filtration rate; PS, performance status according to Eastern Cooperative Oncology Group criteria; CE, cervical esophagus; Ut, upper thoracic esophagus; Mt, middle thoracic esophagus; Lt, lower thoracic esophagus; EGJ, esophago-gastric junction; cT1a, tumor invades the muscularis mucosa; cT1b, tumor invades the submucosa; cT2, tumor invades the muscularis propria; cT3, tumor invades the adventitia; cT4a, tumor invades the pleura, pericardium, azygos vein, diaphragm, or peritoneum; cT4b, tumor invades other adjacent structures, such as the aorta, vertebral body, or trachea; cStage, clinical stage group of squamous cell carcinoma in Union for International Cancer Control 8th edition; cN0, no regional lymph node metastasis; cN1, metastasis in 1-2 regional lymph nodes; cN2, metastasis in 3-6 regional lymph nodes; $\mathrm{cN} 3$, metastasis in 7 or more regional lymph nodes; $\mathrm{cM} 0$, no distant metastasis; cM1-lym, distant lymph node metastasis; CRT, chemoradiotherapy; H-score, histo-score.

All values indicate $\mathrm{n}(\%)$ unless otherwise indicated. 
invasion, lymphatic metastasis, and distant metastasis met a significance level of $0.100(p=0.085, p=0.052$, $p=0.052$, and $p=0.078$, respectively). Subsequent multivariate logistic regression analysis showed that no independent factor was associated with CD44v8-10 expression level. Therefore, CD44v8-10 expression level was not affected by clinicopathological variables including the number of pre-dCRT tumor biopsy specimens, and was an independent factor associated with overall survival of E-SCC patients who received dCRT.

\section{CD44v8-10 expression and 3-year cumulative recurrence}

Forty-two subjects $(42 / 73,58 \%)$ achieved complete response (CR) after dCRT with/without subsequent chemotherapy (regimen: low dose nedaplatin [CDGP] + 5-FU). Among these patients, 15 subjects (15/43, $35 \%$ ) experienced relapse. We analyzed the influence of CD44v8-10 expression on 4 types of recurrence patterns in 13 of the 15 subjects who experienced recurrence within 3 years. As shown in Table 4, the 3-year cumulative lymphatic recurrence rate of subjects with high CD44v8-10 expression was higher than that of subjects with low CD44v8-10 expression (34.9\%, 95\% CI $13.4-57.5$ vs $9.2 \%, 95 \%$ CI $1.5-25.9, p=0.045)$. Our data suggest that patients with high CD44v8-10 expression are at high risk of lymphatic recurrence after dCRT.

\section{Basic study}

\section{Effect of CD44v8-10 on radiation-induced cell death (WST assay)}

We assessed cell proliferation using a WST assay to investigate the influence of $\mathrm{CD} 44 \mathrm{v} 8-10$ on radiationinduced ROS defense. Under low ROS conditions, the CD44v8-10-xCT-GSH inhibitor SSZ $5 \mu \mathrm{M}$ alone did not decrease cell proliferation in CD44v8-10 $0^{\mathrm{High}}$ or CD44v8$10^{\text {Low }}$ cells (CD44v8-10 ${ }^{\text {High }}$ : 100\% for control vs. 98\% for $\mathrm{SSZ}, p=0.762$ in T.Tn [Supplementary Figure 1A], 100\% vs. $104 \%, p=0.130$ in Kyse-3650 [Supplementary Figure 1B]; CD44v8-10 ${ }^{\text {Low: }} 100 \%$ vs. $101 \%, p=0.996$ in T.Tn, $100 \%$ vs. $99 \%, p=0.964$ in Kyse-3650). However, under high ROS conditions due to radiation, SSZ significantly decreased cell proliferation (65\% for radiation alone vs. $54 \%$ for SSZ + radiation, $p=0.001$ for CD44v8-10 $0^{\text {High }}$ T.Tn cells; $74 \%$ vs. $66 \%, p=0.006$ for CD44v8-10 $0^{\text {High }}$ Kyse-3650 cells). In contrast, there was no significant difference in cell proliferation between radiation alone and

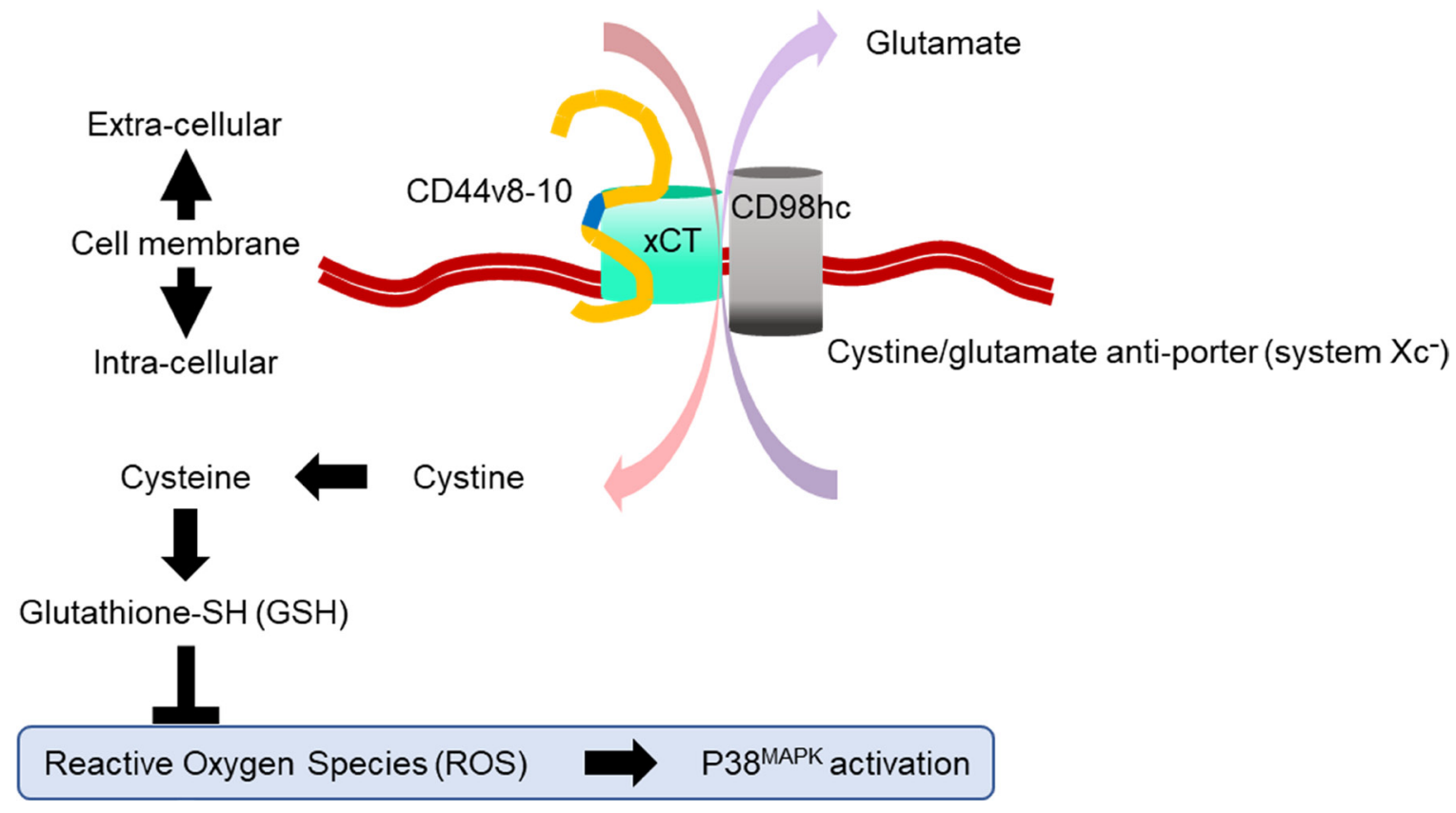

Figure 1: Proposed model of the CD44v8-10-xCT-GSH axis in cancer stem-like cells. One of the mechanisms underlying therapeutic resistance in cancer stem-like cells is their ability to prevent oxidative stress and subsequent cell damage. Oxidative stress occurs when production of reactive oxygen species (ROS) exceeds the capacity of the cellular defense system, which is composed of redox enzymes and other antioxidant molecules. Glutathione-SH (GSH) is an antioxidant molecule and a key player in protecting the cell from anticancer therapy, which induces ROS-mediated cytotoxicity. Synthesis of intracellular GSH is regulated by the availability of intracellular cysteine. System Xc- is an amino acid antiporter that mediates the exchange of extracellular cystine and intracellular glutamate across the cellular plasma membrane. This cystine uptake serves as a rate-limiting step in the provision of intracellular cysteine, which is required for the synthesis of GSH and counteracting the effects of ROS. This Xc- consists of $\mathrm{xCT}$ and CD98hc subunits. $\mathrm{xCT}$ expression at the cell surface is essential for uptake of cystine. xCT-mediated cystine-induced GSH production is important for avoiding ROS-induced p38 ${ }^{\mathrm{MAPK}}$ activation and cell death. CD44v8-10 interacts with and stabilizes xCT, and thereby increases cellular GSH. High CD44v8-10 expression therefore contributes to ROS defense via $\mathrm{xCT}$ of system $\mathrm{Xc}^{-}$and is thought to contribute to cell resistance to ROS-inducing anti-cancer therapy such as chemotherapy and radiotherapy. This figure was summarized from Ishimoto, T., et al. Cancer Cell, 2011. 19(3): p. 387-400. 
Table 2: Relationship between clinicopathological variables and disease-specific survival

\begin{tabular}{|c|c|c|c|c|c|c|}
\hline \multirow{2}{*}{\multicolumn{2}{|c|}{ Variables }} & \multirow[b]{2}{*}{$n$} & \multicolumn{2}{|c|}{ Univariate analysis } & \multicolumn{2}{|c|}{ Multivariate analysis } \\
\hline & & & HR $(95 \%$ CI) & $P$ value & HR $(95 \%$ CI $)$ & $P$ value \\
\hline \multirow{2}{*}{ Gender } & Male & 61 & 1 (reference) & \multirow{2}{*}{0.657} & & \\
\hline & Female & 12 & $0.807(0.313-2.080)$ & & & \\
\hline \multirow{2}{*}{ Age (y) } & $<65$ & 26 & 1 (reference) & \multirow{2}{*}{0.422} & & \\
\hline & $\geq 65$ & 47 & $1.340(0.656-2.738)$ & & & \\
\hline \multirow{2}{*}{ Body surface area $\left(\mathrm{m}^{2}\right)$} & $<1.5$ & 30 & 1 (reference) & \multirow{2}{*}{0.162} & & \\
\hline & $\geq 1.5$ & 43 & $1.664(0.815-3.398)$ & & & \\
\hline \multirow{2}{*}{ eGFR $\left(\mathrm{ml} / \mathrm{min} / 1.73 \mathrm{~m}^{2}\right)$} & $<60$ & 13 & 1 (reference) & \multirow{2}{*}{0.838} & & \\
\hline & $\geq 60$ & 60 & $1.096(0.455-2.643)$ & & & \\
\hline \multirow{2}{*}{ PS } & 0 or 1 & 57 & 1 (reference) & \multirow{2}{*}{$0.004^{*}$} & 1 (reference) & \multirow{2}{*}{0.335} \\
\hline & 2 & 16 & $2.975(1.431-6.186)$ & & $1.461(0.676-3.155)$ & \\
\hline \multirow{2}{*}{ Tumor size $(\mathrm{cm})$} & $<5$ & 35 & 1 (reference) & \multirow{2}{*}{$<0.001^{*}$} & 1 (reference) & \multirow{2}{*}{0.582} \\
\hline & $\geq 5$ & 38 & $3.755(1.784-7.903)$ & & $1.349(0.465-3.913)$ & \\
\hline \multirow{2}{*}{ Histological type } & Differentiated & 64 & 1 (reference) & \multirow{2}{*}{0.876} & & \\
\hline & Un-differentiated & 9 & $1.079(0.418-2.782)$ & & & \\
\hline \multirow{2}{*}{ cStage, UICC 8th } & I-III & 38 & 1 (reference) & \multirow{2}{*}{$<0.001^{*}$} & 1 (reference) & \multirow{2}{*}{$0.024^{*}$} \\
\hline & IVA or IVB (cM1-lym) & 35 & $5.177(2.448-10.946)$ & & $3.536(1.176-10.626)$ & \\
\hline \multirow{2}{*}{ CDGP dose intensity in dCRT (\%) } & $<90$ & 45 & 1 (reference) & \multirow{2}{*}{0.360} & & \\
\hline & $\geq 90$ & 28 & $0.716(0.351-1.463)$ & & & \\
\hline \multirow{2}{*}{ 5-FU dose intensity in dCRT (\%) } & $<90$ & 47 & 1 (reference) & \multirow{2}{*}{0.130} & & \\
\hline & $\geq 90$ & 26 & $0.556(0.261-1.188)$ & & & \\
\hline \multirow{2}{*}{ Radiation dose (Gy) } & $<50.4$ & 1 & 1 (reference) & \multirow{2}{*}{0.548} & & \\
\hline & $\geq 50.4$ & 72 & $20.904(0.001-424858.303)$ & & & \\
\hline \multirow{2}{*}{ Post-dCRT chemotherapy } & - & 17 & 1 (reference) & \multirow{2}{*}{0.646} & & \\
\hline & + & 56 & $0.823(0.358-1.891)$ & & & \\
\hline \multirow{2}{*}{$\begin{array}{c}\text { CD44v8-10 expression } \\
\text { (H-score) }\end{array}$} & Low $(<151)$ & 28 & 1 (reference) & $0002^{*}$ & 1 (reference) & $0013^{*}$ \\
\hline & $\operatorname{High}(\geq 151)$ & 45 & $3.438(1.549-7.631)$ & & $2.844(1.248-6.479)$ & \\
\hline
\end{tabular}

Abbreviations: HR, hazard ratio; CI, confidence interval; eGFR, estimated glomerular filtration rate; PS, performance status according to Eastern Cooperative Oncology Group criteria; cM1-lym, distant lymph node metastasis; cStage, clinical stage in Union for International Cancer Control 8th edition; CDGP, nedaplatin; dCRT, definitive chemoradiotherapy; 5-FU, 5 fluorouracil; H-score, histo-score.

"statistically significant.

$\mathrm{SSZ}+$ radiation conditions in CD44v8-10 Low cells of each cell line $(63 \%$ vs. $66 \%, p=0.981$ for T.Tn; $66 \%$ vs. $67 \%$, $p=0.995$ for Kyse-3650). Therefore, our data suggests that CD44v8-10 might decrease radiation-induced cell death via CD44v8-10-xCT-GSH axis.

\section{The effect of CD44v8-10 on cellular GSH and ROS levels}

We analyzed cellular GSH and ROS levels to confirm the influence of CD44v8-10- xCT-GSH axis. In CD44v8-10 High cells, the GSH level (\% of control) following SSZ $(5 \mu \mathrm{M})$, radiation (2 Gy), and SSZ + radiation treatment was $96 \%, 93 \%$, and $73 \%$ for T.Tn and $94 \%, 89 \%$, and $61 \%$ for Kyse-3650 (Supplementary Figure 2A), respectively. When no radiation was applied, SSZ $5 \mu \mathrm{M}$ alone did not decrease cellular GSH levels compared to control $(100 \%$ for control vs. $96 \%$ for SSZ, $p=0.882$ for T.Tn; $100 \%$ vs. $94 \%, p=0.690$ for Kyse-3650). However, when radiation was applied, SSZ significantly decreased cellular GSH compared to control ( $93 \%$ for radiation vs. $73 \%$ for $\mathrm{SSZ}+$ radiation, $p=0.032$ for T.Tn; $89 \%$ vs. $61 \%, p=0.004$ for Kyse-3650). Therefore, CD44v8-10 significantly decreased cellular GSH via CD44v8-10-xCT-GSH axis.

In CD44v8-10 ${ }^{\text {High }}$ cells, the ROS level (\% of control) following SSZ $(5 \mu \mathrm{M})$, radiation (2 Gy), and SSZ + radiation treatment was $98 \%, 127 \%$, and $170 \%$ for T.Tn and $120 \%, 138 \%$, and $219 \%$ for Kyse-3650 (Supplementary Figure 2B), respectively. When no radiation was applied, SSZ alone did not increase the cellular ROS level $(100 \%$ for control vs. $98 \%$ for SSZ, $p=0.999$ for T.Tn; $100 \%$ vs. $120 \%, p=0.827$ for Kyse-3650). However, when radiation was applied, SSZ significantly increased the cellular ROS level $(127 \%$ for radiation vs. $170 \%$ for SSZ + radiation, $p=$ 0.205 for T.Tn; $138 \%$ vs. $219 \%, p=0.032$ for Kyse-3650). Therefore, CD44v8-10 decreased the cellular ROS level via CD44v8-10-xCT-GSH axis.

Our findings suggest that CD44v8-10 may impair a cell's ROS defense capability via CD44v8-10-xCT-GSH axis and that its expression is correlated with treatment refractoriness, recurrence and prognosis in human E-SCC patients after dCRT. 


\section{DISCUSSION}

\section{Summary}

We demonstrated that CD44v8-10 expression was an independent factor associated with poor prognosis for E-SCC patients treated with dCRT. We revealed that inhibition of the CD44v8-10-xCT-GSH axis may impair the therapeutic resistance in E-SCC CD44v8-10 $0^{\text {High }}$ patients treated with dCRT. To our knowledge, this is the

\section{A Overall}

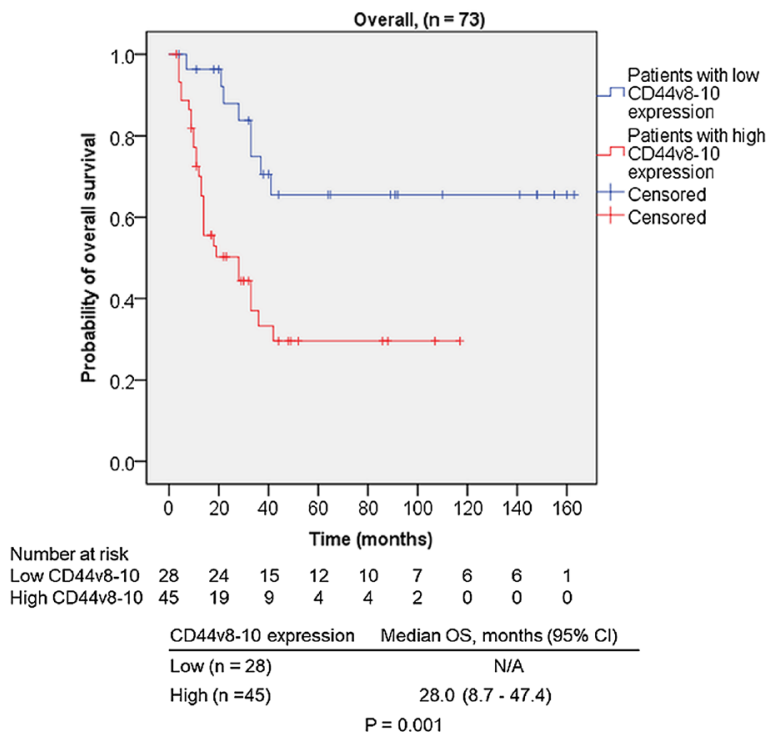

\section{C cStage II and III}

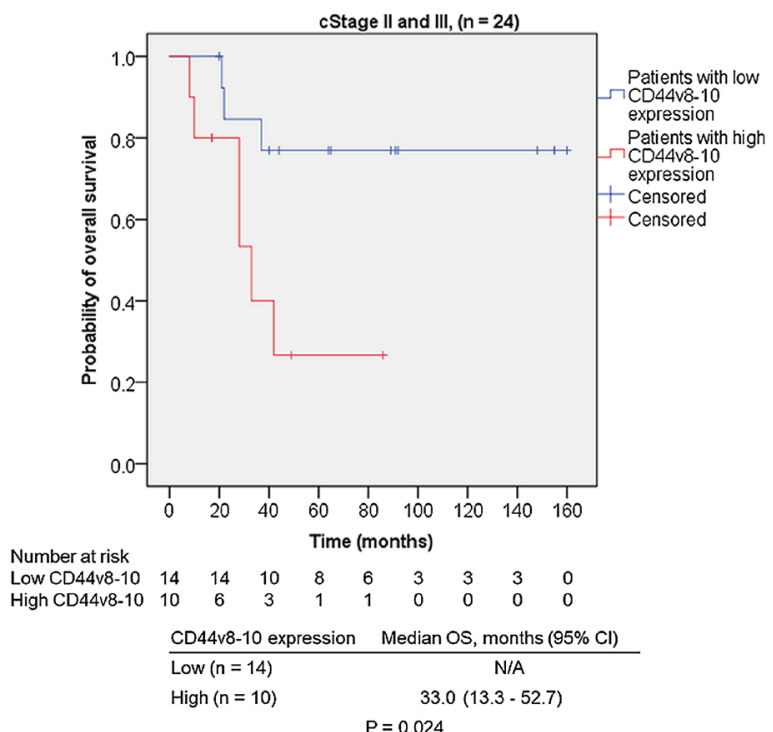

first study to show the influence of CD44v8-10 on the prognosis of esophageal cancer patients after dCRT, and ROS resistance in esophageal cancer cell lines.

\section{CD44v8-10 and prognosis of patients with E-SCC after dCRT}

We investigated the relationship between the CD44v8-10 expression level in pre-dCRT biopsy specimens in E-SCC patients and their post-dCRT overall
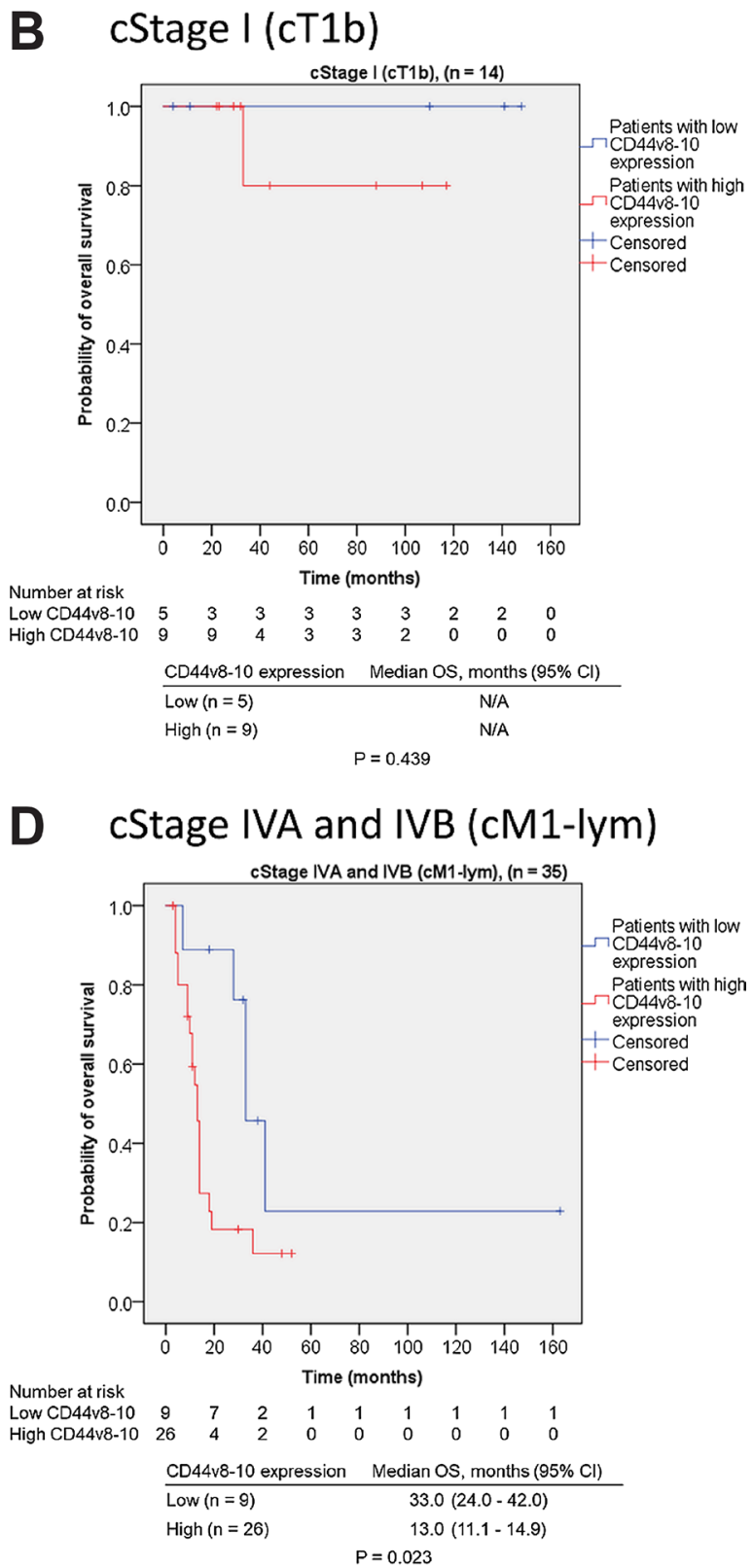

Figure 2: Kaplan-Meier curves of E-SCC patients in relation to CD44v8-10 expression. (A) Among all subjects $(n=73)$, high CD44v8-10 expression in pre-dCRT biopsy specimens was significantly correlated with poor prognosis after dCRT $(p=0.001)$. (B) In cStage I (cT1b) patients, there was no significant difference in overall survival between patients with high and low CD44v8-10 expression $(p=0.439)$. However, in cStage II + III (C) and cStage IVA + IVB (with cM1-lym) patients (D), high CD44v8-10 expression was correlated with poor prognosis ( $p=0.024$ and $p=0.023$, respectively). Abbreviations: E-SCC, esophageal squamous cell carcinoma; dCRT, definitive chemoradiotherapy; cStage, clinical stage in Union for International Cancer Control 8th edition; cT1b, tumor invades the submucosa; cM1lym, distant lymph node metastasis; OS overall survival; CI, confidence interval; N/A, not applicable. 
Table 3: Relationship between CD44v8-10 expression and clinicopathological variables

\begin{tabular}{|c|c|c|c|c|c|c|}
\hline \multirow{3}{*}{\multicolumn{2}{|c|}{ Variables }} & \multicolumn{5}{|c|}{ CD44v8-10 expression } \\
\hline & & \multirow[t]{2}{*}{ Low $n(\%)$} & \multirow[t]{2}{*}{ High $n(\%)$} & \multirow[t]{2}{*}{$P$ value } & \multicolumn{2}{|c|}{$\begin{array}{l}\text { Multivariate analysis } \\
\text { (Logistic regression) }\end{array}$} \\
\hline & & & & & Odds ratio $(95 \% \mathrm{CI})$ & $P$ value \\
\hline Gender & $\begin{array}{c}\text { Male } \\
\text { Female }\end{array}$ & $\begin{array}{r}24(39.3) \\
4(33.3)\end{array}$ & $\begin{array}{r}37(60.7) \\
8(66.7)\end{array}$ & 0.757 & & \\
\hline Age & $\begin{array}{l}<65 \\
\geq 65\end{array}$ & $\begin{array}{l}12(46.2) \\
16(34.0)\end{array}$ & $\begin{array}{l}14(53.8) \\
31(66.0)\end{array}$ & 0.308 & & \\
\hline Tumor size & $\begin{array}{l}<5 \mathrm{~cm} \\
\geq 5 \mathrm{~cm}\end{array}$ & $\begin{array}{l}17(48.6) \\
11(28.9)\end{array}$ & $\begin{array}{l}18(51.4) \\
27(71.1)\end{array}$ & 0.085 & $1.165(0.298-4.551)$ & 0.826 \\
\hline Histological type & $\begin{array}{c}\text { Differentiated } \\
\text { Un-differentiated }\end{array}$ & $\begin{array}{r}24(37.5) \\
4(44.4)\end{array}$ & $\begin{array}{r}40(62.5) \\
5(55.6)\end{array}$ & 0.725 & & \\
\hline Depth of invasion & $\begin{array}{l}\text { cT1b or T2 } \\
\text { cT3-T4b }\end{array}$ & $\begin{array}{l}13(54.2) \\
15(30.6)\end{array}$ & $\begin{array}{l}11(45.8) \\
34(69.4)\end{array}$ & 0.052 & $1.43(0.276-7.404)$ & 0.670 \\
\hline $\begin{array}{l}\text { Lymphatic metastasis } \\
\text { (regional lymph node) }\end{array}$ & $\begin{array}{c}\mathrm{cN} 0 \\
\mathrm{cN} 1-\mathrm{N} 3\end{array}$ & $\begin{array}{l}13(54.2) \\
15(30.6)\end{array}$ & $\begin{array}{l}11(45.8) \\
34(69.4)\end{array}$ & 0.052 & $1.485(0.319-6.911)$ & 0.614 \\
\hline $\begin{array}{l}\text { Distant metastasis } \\
\text { (distant lymph node) }\end{array}$ & $\begin{array}{c}\text { cM0 } \\
\text { cM1 -lym }\end{array}$ & $\begin{array}{r}27(42.9) \\
1(10.0)\end{array}$ & $\begin{array}{r}36(57.1) \\
9(90.0)\end{array}$ & 0.078 & $4.699(0.529-41.744)$ & 0.165 \\
\hline $\begin{array}{l}\text { Number of pre-dCRT } \\
\text { biopsy specimens } \\
\text { including tumor tissue }\end{array}$ & $\begin{array}{c}1 \\
\geq 2\end{array}$ & $\begin{array}{r}5(45.5) \\
23(37.1)\end{array}$ & $\begin{array}{r}6(54.5) \\
39(62.9)\end{array}$ & 0.739 & & \\
\hline
\end{tabular}

Abbreviations: CI, confidence interval; cT1b, tumor invades the submucosa; cT2, tumor invades the muscularis propria; cT3, tumor invades the adventitia; cT4b, tumor invades adjacent structures, such as the aorta, vertebral body, or trachea; cN0, no regional lymph node metastasis; $\mathrm{cN} 1$, metastasis in 1-2 regional lymph nodes; $\mathrm{cN} 3$, metastasis in 7 or more regional lymph nodes; cM0, no distant metastasis; cM1-lym, distant lymph node metastasis; dCRT, definitive chemoradiotherapy.

Table 4: Three-year cumulative incidence of each recurrence pattern for esophageal squamous cell carcinoma (E-SCC) in relation to CD44v8-10 expression

\begin{tabular}{lccc}
\hline & & \multicolumn{3}{c}{ CD44v8-10 expression } \\
\cline { 2 - 4 } Variable & Low $(\mathbf{9 5} \% \mathbf{C I})$ & High $(95 \%$ CI) & $\boldsymbol{P}$ value \\
\hline Local recurrence rate & $18.4 \%(5.5-37.3 \%)$ & $29.4 \%(9.9-52.4 \%)$ & 0.387 \\
Lymphatic recurrence rate & $9.2 \%(1.5-25.9 \%)$ & $34.9 \%(13.4-57.5 \%)$ & $0.045^{*}$ \\
Hematogenous recurrence rate & $4.6 \%(0.3-19.5 \%)$ & $13.6 \%(1.9-36.8 \%)$ & 0.369 \\
Disseminated recurrence rate & $14.0 \%(3.3-32.2 \%)$ & $21.9 \%(4.7-47.0 \%)$ & 0.556 \\
\hline
\end{tabular}

Abbreviations: CI, confidence interval

*statistically significant.

survival. We found that high CD44v8-10 expression was independent of conventional clinicopathological variables and was strongly correlated with poor prognosis (Table 2). High CD44v8-10 expression was significantly correlated with poor survival in cStage II + III and cStage IVA + IVB (cM1-lym) patients (Figure 2C and 2D). Interestingly, cStage II + III patients with low CD44v8-10 expression appeared to have remarkably better survival than patients with high CD44v8-10 expression. dCRT eradicated most of the E-SCC cells in patients with cStage II or III E-SCC, and a high CR rate was achieved. However, selective survival of a few cancer stem-like cells with high
CD44v8-10 expression might be the cause of post-CR recurrence.

\section{CD44v8-10-xCT-GSH axis inhibition decreased ROS defense}

Intracellular GSH reportedly functions to protect cells against radiation-induced ROS [19]. Our findings were consistent with this report; we found that decreasing cystine-induced GSH levels with an CD44v8-10-xCT-GSH axis inhibitor (SSZ) weakened the cell's defense against radiation-induced ROS in CD44v8-10 $0^{\text {High }}$ cells, which 
consequently decreased cell survival (Supplementary Figure 1). A previous report showed that SSZ suppresses the proliferation of CD44v8-10-expressing tumor cells in a mouse xenograft model [18]. Because high expression of CD44v8-10 was correlated with poor prognosis of E-SCC patients, the clinical usefulness of CD44v8-10-xCT-GSH axis inhibitors such as SSZ in dCRT for E-SCC patients should be verified in future clinical studies.

\section{Limitations}

Our data should be interpreted in the context of several limitations. First, our study was retrospective, and we were therefore unable to address all confounding biases. To attempt to minimize the influence of these biases, we recruited a large number of consecutive patients and adopted a solid outcome endpoint in overall survival. Second, H-score $\geq 151$ was provisionally used as the definition for high CD44v8-10 expression, which has not been sufficiently verified. The threshold value may differ according to the antibody used for immunohistochemistry, tissue size of the specimen, or ethnic group of the subjects. Third, although, CDDP + 5 -FU is the global standard combination regimen for dCRT, we have used a low dose CDGP + 5-FU regimen for renal protection. However, given that our aim was

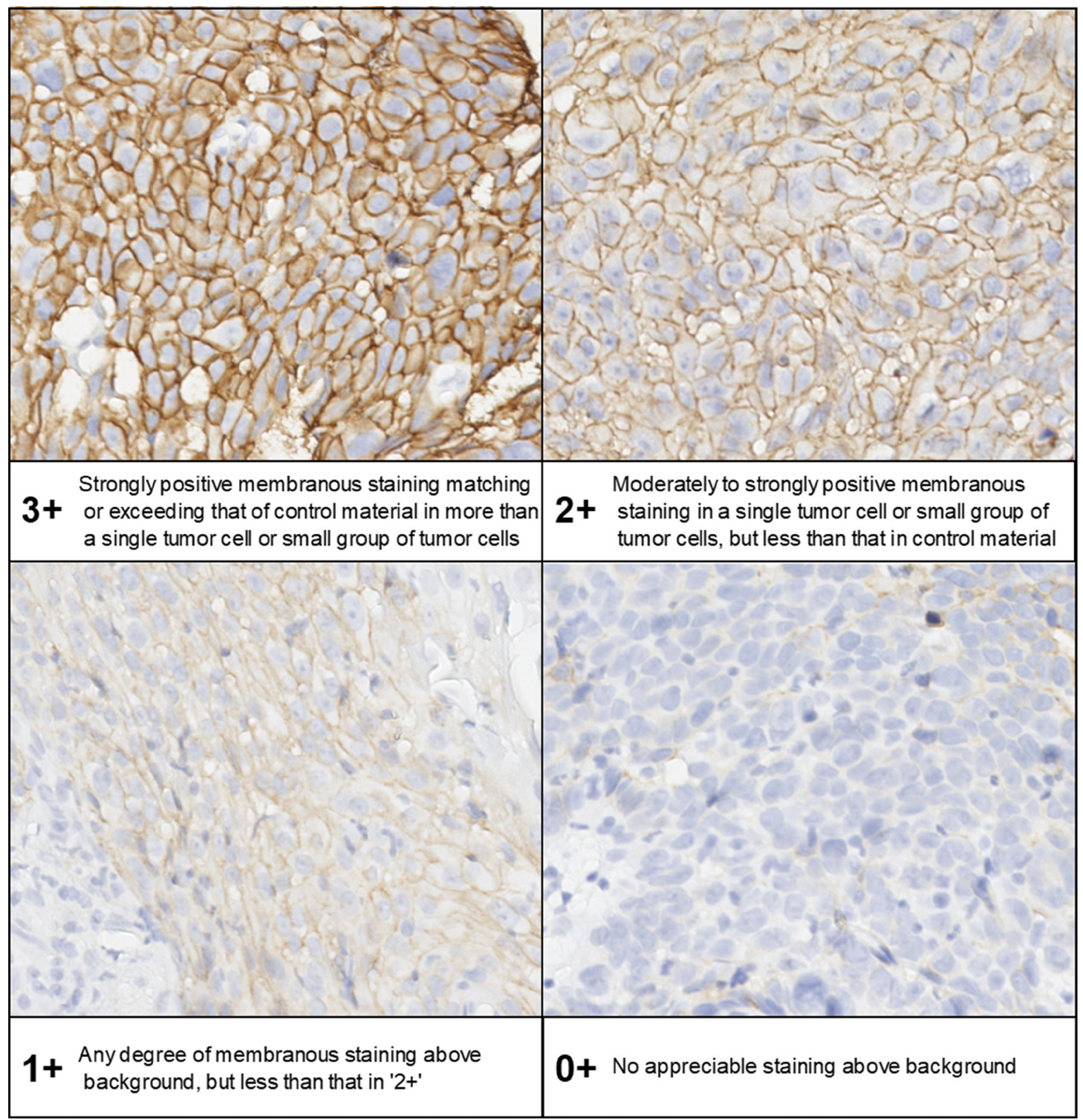

Figure 3: Ad hoc semiquantitative scoring scheme for CD44v8-10 expression. Expression of CD44v8-10 on tumor cell membranes was determined using a $0+$ to $3+$ scale. The histo-score $(\mathrm{H}$-score) for each patient was calculated using the following formula: $(\%$ of cells $3+) \times 3+(\%$ of cells $2+) \times 2+(\%$ of cells $1+)$. H-score $\geq 151$ was provisionally defined as high CD44v8-10 expression. 
to exam the influence of $\mathrm{CD} 44 \mathrm{v} 8-10$ on reactivity for radiotherapy-induced ROS in E-SCC, we do not think that enrolling these patients affected our results. Fourth, this study included few young subjects [mean \pm SD (y) $=69.0 \pm 8.2$ ], and male subjects were in the majority (male: $83.6 \%$, female: $16.4 \%$ ). Fifth, we did not examine the expression of molecules other than CD44v8-10 in CD44v8-10 $0^{\text {High }}$ and CD44v8-10 ${ }^{\text {Low }}$ subpopulations of each cell line.

\section{CONCLUSIONS}

Our study suggests that therapeutic resistance by CD44v8-10-xCT-GSH axis correlates with poor prognosis after dCRT in E-SCC patients. Therefore, this system may be a useful therapeutic target. To improve overall survival, CD44v8-10-xCT-GSH axis-targeted therapies such as SSZ must be concomitantly administered with other successful anti-cancer therapies because SSZ has no effect on cancer cells with low CD44v8-10 expression. Although dCRT appears to satisfy this essential condition, the clinical efficacy of the combined use of SSZ and dCRT in E-SCC patients should be verified in future studies.

\section{MATERIALS AND METHODS}

\section{Ethics approval}

The study protocol was approved by the Human Institutional Review Board of the Hamamatsu University School of Medicine, Hamamatsu, Japan (E16-269).

\section{Quality management}

All authors completed the Good Clinical Practice Education and Training (CITI Japan, e-learning program) prior to the start of the study.

\begin{abstract}
Aims
The study consisted of a clinical study and additional basic study. The aim of the clinical study was to examine the relationship between the CD44v8-10 expression level and overall survival of E-SCC patients after dCRT. The aim of the basic study was to investigate the influence of SSZ on the radiation induced-ROS defense capability of CD44v8-10 ${ }^{\text {High }}$ and CD44v8-10 ${ }^{\text {Low }}$ cells.
\end{abstract}

\section{Clinical study}

\section{Subjects}

We identified 597 subjects following a search of our hospital database using the keyword "esophageal cancer" and search span "Jan. 2003 to Jun. 2014". In accordance with the inclusion criteria summarized in Supplementary
Table 1, 393 subjects with cStage I (cT1b) to cStage IVA and cStage IVB (cM1-lym) E-SCC were selected (Supplementary Figure 3). Among these patients, 78 subjects who received dCRT (regimen: low dose CDGP +5 -FU) as first line treatment were enrolled. However, 5 subjects $(5 / 78,6.4 \%)$ were excluded in accordance with the exclusion criteria in Supplementary Table 1. Data from the remaining 73 subjects were used to examine the relationship between CD44v8-10 expression and overall survival.

\section{Evaluation of CD44v8-10 and overall survival}

We performed immunohistochemical staining of paraffin-blocked specimens obtained by esophagoscopy before dCRT using an anti-CD44v8-10 antibody (clone RV3; LKG-M001, COSMO BIO CO., LTD. Tokyo, Japan) as previously reported $[17,20,21]$. Two pathologists (S. B. and H. S.) calculated the CD44v8-10 expression level for each patient using a semi-quantitative method and expressed this as a H-score [22, 23] (Figure 3). The relationship between the CD44v8-10 expression level and overall survival was analyzed. Patients' medical data were retrospectively obtained using the hospital's information system.

\section{Performance status evaluation}

The PS of each subject was evaluated using the Eastern Cooperative Oncology Group (ECOG) criteria [24]. The predCRT PS of all 73 subjects was within the $0-2$ range.

\section{Chemoradiotherapy}

Patients were treated with low dose CDGP +5 -FU + radiotherapy as dCRT. CDGP ( $7 \mathrm{mg} / \mathrm{m}^{2} /$ day $)$ was administered on Day 1, 8, 15, and 22. 5-FU (350 mg/ $\mathrm{m}^{2} /$ day) was administered as a continuous intravenous infusion for the first 5 days of weeks 1-4 (i.e., Days $1-5,8-12,15-19$, and 22-26) $[25,26]$. The total dosage of CDGP and 5-FU in each patient was calculated from patient records. Dose intensity was calculated using following formulae:

CDGP dose intensity $(\%)=($ total dosage of CDGP $[\mathrm{mg}] / 7\left[\mathrm{mg} / \mathrm{m}^{2} /\right.$ day $] \times$ body surface area $\left[\mathrm{m}^{2}\right] \times 4$ [days $\left.]\right) \times 100$

5 -FU dose intensity $(\%)=($ total dosage of 5 -FU $[\mathrm{mg}] / 350\left[\mathrm{mg} / \mathrm{m}^{2} /\right.$ day $] \times$ body surface area $\left[\mathrm{m}^{2}\right] \times 20$ [days] $) \times 100$.

In general, a total of 60 Gy of radiation was delivered to each patient and at least two courses of additional chemotherapy were given after dCRT. Therapeutic effects were assessed by computed tomography (CT) and esophagoscopy in each patient every 4-6 months after completion of dCRT. The relationship between overall survival and CD44v8-10 expression was analyzed.

\section{Sample power}

Consultation with a biostatistician (E.O.) recommended an ideal sample size of at least 30 (15 patients with high CD44v8-10 expression and 15 with low CD44v8-10 expression). We assumed the frequency of high CD44v8-10 expression in E-SCC patients was about $40 \%$ (i.e., almost 
the same as that in head and neck cancer patients) [27]. We therefore needed to secure at least 37 eligible patients $(15 / 0.4)$ to enroll 15 E-SCC patients with each CD44v8-10 expression level. About two-thirds (66\%) of dCRT for esophageal cancer patients in our hospital received the low dose CDGP $+5-\mathrm{FU}$ regimen. We therefore concluded that at least 57 patients were needed (37/0.66).

\section{Statistical analysis}

Age, height, weight, and estimated glomerular filtration rate (eGFR) were reported as mean \pm standard deviation (SD). The number of pre-dCRT tumor biopsy samples and CD44v8-10 expression (H-score) were reported as median and range. Categorical parameters were assessed using the chi-squared test or Fisher's exact test as appropriate. The association between clinical variables and disease-specific survival was assessed by univariate analysis and multivariate analysis using the Cox proportional hazards model. Kaplan-Meier survival curves were constructed to compare patients with high and low CD44v8-10 expression. Statistical significance was calculated using the log-rank test. We also analyzed the three-year cumulative incidence rate of each recurrence pattern in relation to CD44v8-10 expression using the competing-risk method (Gray test) in which death from other causes was considered a competing risk. All statistical calculations except the Gray test were performed using IBM SPSS Statistics version 23 (IBM, Madison Ave, NC, USA). All $p$ values were two-tailed, and $p<0.050$ indicated statistical significance. The Gray test and number of patients at risk in the Kaplan-Meier survival curve were calculated using EZR (Saitama Medical Center, Jichi Medical University, Saitama, Japan).

\section{Basic study}

\section{Cell culture}

Human esophageal cancer (SCC) cell lines including T.T, T.Tn, and Kyse-3650 were purchased from the Japanese Collection of Research Bioresources Cell Bank (Osaka, Japan). T.T and T.Tn were cultured in a 1:1 mixture of Dulbecco's modified Eagle's medium and Ham's F12 medium (D-MEM/Ham's F-12 with L-glutamine and phenol red, 048-29785, Wako Pure Chemical Industries, Ltd., Osaka, Japan) containing 10\% fetal bovine serum (FBS; 26140079, Gibco ${ }^{\circledR}$, Thermo Fisher Scientific Inc., Waltham, MA, USA) and 1\% antibiotic-antimycotic (15240-062, Gibco ${ }^{\circledR}$, Thermo Fisher Scientific Inc.). Kyse3650 was cultured in a 1:1 mixture of Ham's F12 medium (with L-glutamine and phenol red, 087-08335, Wako Pure Chemical Industries, Ltd.) and Roswell Park Memorial Institute 1640 medium (with L-glutamine and phenol red, 189-02025, Wako Pure Chemical Industries, Ltd.) containing 5\% FBS and 1\% antibiotic-antimycotic. Cells were cultured in a humidified incubator (MCO-19AIC-UV, Panasonic Corp., Osaka, Japan) at $37^{\circ} \mathrm{C}$.
Cell sorting for CD44v8-10 ${ }^{\text {High }}$ and CD44v8-10 ${ }^{\text {Low }}$ subpopulations

Cell sorting was performed for cancer cell lines (T.Tn, T.T, and Kyse-3650) using clone RV-3 in accordance with the manufacturer's protocol [28]. The parental cells of each cell line were added to clone RV-3 (1:333 dilution) and incubated with gentle agitation for 45 minutes at $4^{\circ} \mathrm{C}$. The cells were subsequently incubated with phycoerythrin (PE)-labeled secondary antibody solution (1:200 dilution; 712-116-153, Jackson ImmunoResearch Laboratories, Inc., West Grove, PA, USA) without agitation for 45 minutes at $4{ }^{\circ} \mathrm{C}$ in the dark. Among these cells, subpopulations of CD44v8-10 ${ }^{\text {High }}$ and CD44v8-10 ${ }^{\text {Low }}$ were sorted aseptically using a fluorescence-activated cell sorter (FACS; FACS Aria SORP, Becton, Dickinson and Company, Franklin Lakes, NJ, USA). These flow cytometry data were analyzed using a software package (FlowJo ver.10, Tomy Digital Biology, Co., Ltd., Tokyo, Japan) (Supplementary Figure 4). We confirmed the expression of CD44v8-10 in CD44v8-10 $0^{\text {High }}$ and CD44v8-10 ${ }^{\text {Low }}$ cells using TaqMan-based real-time quantitative reverse transcription polymerase chain reaction (real-time qRTPCR) (Supplementary Figure 5) and FACS analysis after scale-up (Supplementary Figure 6).

\section{Analysis of water soluble tetrazolium salts-8 assay}

To evaluate the influence of CD44v8-10 on radiation-induced ROS in each cell line, we performed a cytotoxicity test using a commercially available WST cell proliferation assay kit (Cell Counting Kit-8, 347-07621, Dojindo Molecular Technologies, Inc., Kumamoto, Japan). CD44v8-10 $0^{\text {High }}$ and CD44v8-10 ${ }^{\text {Low }}$ cells in each cell line (T.Tn and Kyse-3650) were seeded in 96-well clear plates (rows 2-7 of columns 2, 5, 8, and 11; $3 \times$ $10^{4}$ cells $/ \mathrm{ml} ; 100 \mu \mathrm{l} /$ well; 167008, Nunc ${ }^{\mathrm{TM}}$, Thermo Fisher Scientific Inc.) and administered the following treatments: (i) control (rows 2-7 of column 11), (ii) SSZ $5 \mu \mathrm{M}$ (rows $2-7$ of column 8), (iii) radiation 2 Gy (rows 2-7 of column 5), and (iv) SSZ + radiation (rows 2-7 of column 2). To avoid edge effects, phosphate buffered saline (PBS; $100 \mu \mathrm{l} /$ well) was loaded into the remaining vacant wells. As shown in Supplementary Figure 7A, 2 Gy radiation was given to groups (iii) and (iv) three times every 24 hours at $150 \mathrm{kV}, 20 \mathrm{~mA}$, irradiation distance: $31 \mathrm{~cm}$, and irradiation time: $70 \mathrm{sec}$ (XB160CP, Chubu Medical Co. Ltd., Mie, Japan). During each radiation dose, the wells of groups (i) and (ii) were shielded by a lead board of 2-mm thickness. In accordance with the manufacturer's protocol [29], WST was added to each well $(10 \mu \mathrm{l} /$ well $)$ at 144 hours after cell seeding. After 2 hours of incubation, absorbance at $450 \mathrm{nM}$ was measured using a microplate reader (Synergy H1, Biotek Instruments, Inc., Winooski, VT, USA). This method was repeated for each cell line ( $n=6$, in triplicate), and the difference in cell proliferation levels were statistically analyzed among the four treatment groups. 


\section{Analysis of cellular GSH and ROS levels}

We measured cellular GSH levels to evaluate the influence of SSZ on ROS resistance induced by radiation in CD44v8-10 ${ }^{\text {High }}$ cells of each cell line (T.Tn and Kyse3650). CD44v8-10 ${ }^{\text {High }}$ cells in each cell line (T.Tn and Kyse-3650) were seeded in separate 96-well microplates and treated with the regimen shown in Supplementary Figure 7B. GSH and ROS were measured using commercially available kits (GSH-Glo ${ }^{\mathrm{TM}}$ Glutathione Assay kit, V6911, Promega Co., Fitchburg, WI, USA, and OxiSelect ${ }^{\mathrm{TM}}$, STA-342, Cell Biolabs, Inc., San Diego, CA, USA, respectively) in triplicate.

\section{Statistics}

Significant differences in cell viability and levels of GSH and ROS among cells treated with/without SSZ and/or radiation were determined using one-way analysis of variance with post-hoc Tukey's honest significant difference (HSD) test. All statistical calculations were performed using IBM SPSS Statistics version 23 (IBM, Madison Ave, NC, USA). All $p$ values were two-tailed, and $p<0.050$ indicated statistical significance.

\section{Abbreviations}

Ce, cervical esophagus; CDDP, cisdiamminedichloro-platinum (cisplatin); CDGP, cisdiammine-glycolatoplatinum (nedaplatin); CD44v8-10, CD44 isoform containing variant exon 8 to 10; CI, confidence interval; cM1-lym, cM1 with distant lymph node metastasis; cN0, no regional lymph node metastasis; cN1, metastasis in 1-2 regional lymph nodes; cN2, metastasis in 3-6 regional lymph nodes; cN3, metastasis in 7 or more regional lymph nodes; CPT-11, irinotecan; $\mathrm{CR}$, complete response; cStage, clinical stage group of squamous cell carcinoma in Union for International Cancer Control 8th edition; CT, computed tomography; cT1a, tumor invades the muscularis mucosa; cT1b, tumor invades the submucosa; cT2, tumor invades the muscularis propria; cT3, tumor invades the adventitia; cT4a, tumor invades the pleura, pericardium, azygos vein, diaphragm, or peritoneum; cT4b, tumor invades other adjacent structures, such as the aorta, vertebral body, or trachea; dCRT, definitive chemoradiotherapy; D-MEM, Dulbecco's Modified Eagle's Medium; ECOG, Eastern Cooperative Oncology Group; eGFR, estimated glomerular filtration rate; EGJ, esophago-gastric junction; Em, emission wavelength; E-SCC, esophageal squamous cell carcinoma; Ex, excitation wavelength; FACS, fluorescence-activated cell sorter; FBS, fetal bovine serum; GSH, glutathione-SH; H-score, histo-score; $\mathrm{HR}$, hazard ratio; HSD, honest significant difference; HUSM, Hamamatsu University school of Medicine; JSCO, Japanese Society of Clinical Oncology; Lt, lower thoracic esophagus; Mt, middle thoracic esophagus; N/A, not applicable; PE, phycoerythrin; PS, performance status according to Eastern Cooperative Oncology Group criteria; qRT-PCR, quantitative reverse transcription polymerase chain reaction; RECIST, Response Evaluation Criteria in Solid Tumors; ROS, reactive oxygen species; RV-3 clone, anti-CD44v8-10 antibody; SCC, squamous cell carcinoma; SSZ, sulfasalazine; UICC, Union for International Cancer Control; Ut, upper thoracic esophagus; WST, water soluble tetrazolium salt-8; 5-FU, 5-fluorouracil.

\section{Author contributions}

T. K. and T. F. wrote the article; T. K., T. F., M. Y., T. S., T. U., S. T., Y. H., M. I., S. O., K. S., S. B., H. S and H. M. designed the research; T. K., M. Y., T. S., T. U., S. B., H. S. and T. F. performed the research; T. K., M. Y., T. S., T. U., S. T., Y. H., M. I., S. O., K. S., H. S., S. B., H. M., and T. F. analyzed the data; S. B. and H. S. contributed to the analysis of histo-score.

\section{ACKNOWLEDGMENTS}

We thank Mr. Ryo Horiguchi and Ms. Aya Kitamoto at Advanced Research Facilities and Services for their excellent technical assistance. We also thank Mr. Hisaki Igarashi at Department of Tumor Pathology for his valuable assistance with immunohistochemical staining.

\section{CONFLICTS OF INTEREST}

None of the authors had any conflicts of interest related to this study.

\section{FUNDING}

This work was supported by a grant-in-aid from the Ministry of Education, Culture, Sports, Science and Technology of Japan (20590718).

\section{REFERENCES}

1. Gunthert U, Hofmann M, Rudy W, Reber S, Zoller M, Haussmann I, Matzku S, Wenzel A, Ponta H, Herrlich P. A new variant of glycoprotein CD44 confers metastatic potential to rat carcinoma cells. Cell. 1991; 65:13-24.

2. Ishimoto T, Oshima H, Oshima M, Kai K, Torii R, Masuko T, Baba H, Saya H, Nagano O. CD44+ slow-cycling tumor cell expansion is triggered by cooperative actions of Wnt and prostaglandin E2 in gastric tumorigenesis. Cancer Sci. 2010; 101:673-8. https://doi.org/10.1111/j.1349-7006.2009.01430.x.

3. Ponta H, Sherman L, Herrlich PA. CD44: from adhesion molecules to signalling regulators. Nat Rev Mol Cell Biol. 2003; 4:33-45. https://doi.org/10.1038/nrm1004.

4. Mayer B, Jauch KW, Gunthert U, Figdor CG, Schildberg FW, Funke I, Johnson JP. De-novo expression of CD44 and survival in gastric cancer. Lancet. 1993; 342:1019-22. 
5. Herskovic A, Martz K, Al-Sarraf M, Leichman L, Brindle J, Vaitkevicius V, Cooper J, Byhardt R, Davis L, Emami B. Combined chemotherapy and radiotherapy compared with radiotherapy alone in patients with cancer of the esophagus. N Engl J Med. 1992; 326:1593-8. https://doi.org/10.1056/ nejm199206113262403.

6. Cooper JS, Guo MD, Herskovic A, Macdonald JS, Martenson JA Jr, Al-Sarraf M, Byhardt R, Russell AH, Beitler JJ, Spencer S, Asbell SO, Graham MV, Leichman LL. Chemoradiotherapy of locally advanced esophageal cancer: long-term follow-up of a prospective randomized trial (RTOG 85-01). Radiation Therapy Oncology Group. JAMA. 1999; 281:1623-7.

7. Ohtsu A, Boku N, Muro K, Chin K, Muto M, Yoshida S, Satake M, Ishikura S, Ogino T, Miyata Y, Seki S, Kaneko K, Nakamura A. Definitive chemoradiotherapy for T4 and/or M1 lymph node squamous cell carcinoma of the esophagus. J Clin Oncol. 1999; 17:2915-21. https://doi.org/10.1200/jco.1999.17.9.2915.

8. Ishida K, Ando N, Yamamoto S, Ide H, Shinoda M. Phase II study of cisplatin and 5-fluorouracil with concurrent radiotherapy in advanced squamous cell carcinoma of the esophagus: a Japan Esophageal Oncology Group (JEOG)/ Japan Clinical Oncology Group trial (JCOG9516). Jpn J Clin Oncol. 2004; 34:615-9. https://doi.org/10.1093/jjco/hyh107.

9. Nishimura Y, Suzuki M, Nakamatsu K, Kanamori S, Yagyu Y, Shigeoka H. Prospective trial of concurrent chemoradiotherapy with protracted infusion of 5-fluorouracil and cisplatin for T4 esophageal cancer with or without fistula. Int J Radiat Oncol Biol Phys. 2002; 53:134-9.

10. Shinoda M, Ando N, Kato H, Tsubosa Y, Minashi K, Watanabe G, Ikeda K, Kawano T, Nakamura K, Fukuda H. A multicenter randomized phase II (rPII)/III study comparing concurrent chemoradiotherapy (CRT) with low-dose cisplatin plus continuous infusion of 5-fluorouracil (LDPF) and standard-dose PF (SDPF) for locally advanced unresectable squamous cell carcinoma of the thoracic esophagus (JCOG0303). Journal of Clinical Oncology. 2010; 28:4053. https://doi.org/10.1200/jco.2010.28.15_suppl.4053.

11. Nishimura $Y$, Mitsumori $M$, Hiraoka $M$, Koike $R$, Nakamatsu K, Kawamura M, Negoro Y, Fujiwara K, Sakurai H, Mitsuhashi N. A randomized phase II study of cisplatin/5FU concurrent chemoradiotherapy for esophageal cancer: Short-term infusion versus protracted infusion chemotherapy (KROSG0101/JROSG021). Radiother Oncol. 2009; 92:260 5. https://doi.org/10.1016/j.radonc.2008.12.012.

12. Nishimura $Y$, Hiraoka M, Koike R, Nakamatsu K, Itasaka S, Kawamura M, Negoro Y, Araki N, Ishikawa H, Fujii T, Mitsuhashi N. Long-term follow-up of a randomized Phase II study of cisplatin/5-FU concurrent chemoradiotherapy for esophageal cancer (KROSG0101/JROSG021). Jpn J Clin Oncol. 2012; 42:807-12.

13. Kato H, Sato A, Fukuda H, Kagami Y, Udagawa H, Togo A, Ando N, Tanaka O, Shinoda M, Yamana H, Ishikura S. A phase II trial of chemoradiotherapy for stage I esophageal squamous cell carcinoma: Japan Clinical Oncology Group
Study (JCOG9708). Jpn J Clin Oncol. 2009; 39:638-43. https://doi.org/10.1093/jjco/hyp069.

14. Kato K, Muro K, Minashi K, Ohtsu A, Ishikura S, Boku N, Takiuchi H, Komatsu Y, Miyata Y, Fukuda H; Gastrointestinal Oncology Study Group of the Japan Clinical Oncology Group (JCOG). Phase II study of chemoradiotherapy with 5-fluorouracil and cisplatin for Stage II-III esophageal squamous cell carcinoma: JCOG trial (JCOG 9906). Int J Radiat Oncol Biol Phys. 2011; 81:684-90. https://doi.org/10.1016/j.ijrobp.2010.06.033.

15. Kato $\mathrm{K}$, Nakajima $\mathrm{TE}$, Ito $\mathrm{Y}$, Katada $\mathrm{C}$, Ishiyama $\mathrm{H}$, Tokunaga SY, Tanaka M, Hironaka S, Hashimoto T, Ura T, Kodaira T, Yoshimura K. Phase II study of concurrent chemoradiotherapy at the dose of 50.4 Gy with elective nodal irradiation for Stage II-III esophageal carcinoma. Jpn J Clin Oncol. 2013; 43:608-15. https://doi.org/10.1093/jjco/hyt048.

16. Japan Society of Clinical Oncology. Esophageal Cancer Clinical Practice Guidelines (Japanese article). Available at: http://jsco-cpg.jp/guideline/09html. 2017; Ver. 4.

17. Ishimoto $\mathrm{T}$, Nagano $\mathrm{O}$, Yae $\mathrm{T}$, Tamada $\mathrm{M}$, Motohara $\mathrm{T}$, Oshima H, Oshima M, Ikeda T, Asaba R, Yagi H, Masuko T, Shimizu T, Ishikawa T, et al. CD44 variant regulates redox status in cancer cells by stabilizing the $\mathrm{xCT}$ subunit of system $\mathrm{xc}(-)$ and thereby promotes tumor growth. Cancer Cell. 2011; 19:387-400. https://doi.org/10.1016/j.ccr.2011.01.038.

18. Yoshikawa M, Tsuchihashi K, Ishimoto T, Yae T, Motohara T, Sugihara E, Onishi N, Masuko T, Yoshizawa K, Kawashiri S, Mukai M, Asoda S, Kawana H, et al. xCT inhibition depletes CD44v-expressing tumor cells that are resistant to EGFR-targeted therapy in head and neck squamous cell carcinoma. Cancer Res. 2013; 73:1855-66. https://doi.org/10.1158/0008-5472.can-12-3609-t.

19. Diehn M, Cho RW, Lobo NA, Kalisky T, Dorie MJ, Kulp AN, Qian D, Lam JS, Ailles LE, Wong M, Joshua B, Kaplan MJ, Wapnir I, et al. Association of reactive oxygen species levels and radioresistance in cancer stem cells. Nature. 2009; 458:780-3. https://doi.org/10.1038/nature07733.

20. Tanabe KK, Ellis LM, Saya H. Expression of CD44R1 adhesion molecule in colon carcinomas and metastases. Lancet. 1993; 341:725-6.

21. Yae T, Tsuchihashi K, Ishimoto T, Motohara T, Yoshikawa M, Yoshida GJ, Wada T, Masuko T, Mogushi K, Tanaka H, Osawa T, Kanki Y, Minami T, et al. Alternative splicing of CD44 mRNA by ESRP1 enhances lung colonization of metastatic cancer cell. Nat Commun. 2012; 3:883. https://doi.org/10.1038/ncomms 1892.

22. Kim SH, Park WS, Park EY, Park B, Joo J, Joung JY, Seo HK, Lee KH, Chung J. The prognostic value of BAP1, PBRM1, pS6, PTEN, TGase2, PD-L1, CA9, PSMA, and Ki-67 tissue markers in localized renal cell carcinoma: A retrospective study of tissue microarrays using immunohistochemistry. PLoS One. 2017; 12:e0179610. https://doi.org/10.1371/journal.pone.0179610.

23. Choueiri TK, Figueroa DJ, Fay AP, Signoretti S, Liu Y, Gagnon R, Deen K, Carpenter C, Benson P, Ho TH, Pandite L, de Souza 
P, Powles T, et al. Correlation of PD-L1 tumor expression and treatment outcomes in patients with renal cell carcinoma receiving sunitinib or pazopanib: results from COMPARZ, a randomized controlled trial. Clin Cancer Res. 2015; 21:1071-7. https://doi.org/10.1158/1078-0432.ccr-14-1993.

24. Oken MM, Creech RH, Tormey DC, Horton J, Davis TE, McFadden ET, Carbone PP. Toxicity and response criteria of the Eastern Cooperative Oncology Group. Am J Clin Oncol. 1982; 5:649-55.

25. Inaba H, Tsuda T, Miyazaki A, Watanabe Y, Nakaya S, Koitabashi Y, Ogihara K, Hara T, Kato N, Kobayashi Y, Nakagawa T, Kitajima S, Endo T, et al. [Clinical study of the combination of small amount of nedaplatin (CDGP)/5FU with radiation for the treatment of esophageal cancer] [Article in Japanese]. Nihon Shokakibyo Gakkai Zasshi. 2002; 99:1191-6.

26. Osawa S, Furuta T, Sugimoto K, Kosugi T, Terai T, Yamade M, Takayanagi Y, Nishino M, Hamaya Y, Kodaira C, Yamada T, Iwaizumi M, Takagaki K, et al. Prospective study of daily low-dose nedaplatin and continuous 5-fluorouracil infusion combined with radiation for the treatment of esophageal squamous cell carcinoma. BMC Cancer. 2009; 9:408. https://doi.org/10.1186/1471-2407-9-408.

27. Aso T, Matsuo M, Kiyohara H, Taguchi K, Rikimaru F, Shimokawa M, Segawa Y, Higaki Y, Umeno H, Nakashima T, Masuda M. Induction of CD44 variant 9-expressing cancer stem cells might attenuate the efficacy of chemoradioselection and Worsens the prognosis of patients with advanced head and neck cancer. PLoS One. 2015; 10:e0116596. https://doi.org/10.1371/journal.pone.0116596.

28. Cosmo Bio Co. LCBAC, Tokyo, Japan. Anti Human CD44 v9 [(v8-10), Clone : RV3] test procedure. Available at: https://search.cosmobio.co.jp/cosmo_search_p/search gate2/docs/CAC_LKGM001.20130626.pdf.

29. Dojindo Molecular Technologies I. Cell Counting Kit-8, Measuring Cell Viability / Cytotoxicity. Available at: https:// www.dojindo.com/Protocol/Cell-Proliferation-Protocol.pdf. 